\title{
Estimating the Cost of Cancer Care in British Columbia and Ontario: A Canadian Inter-Provincial Comparison
}

\section{Estimation du coût des soins contre le cancer en Colombie-Britannique et en Ontario : une comparaison interprovinciale au Canada}

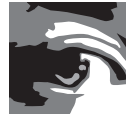 \\ ClAire DE OLIVEIRA, MA, PhD \\ Institute for Clinical Evaluative Sciences, Sunnybrook Health Sciences Centre for Addiction and Mental Health \\ Institute of Health Policy, Management and Evaluation, University of Toronto \\ Toronto, ON \\ REKA PATAKY, BSC, MSC \\ Canadian Centre for Applied Research in Cancer Control, British Columbia Cancer Agency \\ Vancouver, BC \\ KAREN E. BREMNER, BSC \\ University Health Network, Toronto Health Economics and Technology Assessment Collaborative \\ Toronto, ON \\ JAGADISH RANGREJ,MSC, MMATH \\ Institute for Clinical Evaluative Sciences, Sunnybrook Health Sciences Centre \\ Toronto, ON \\ KELVIN K.W. CHAN, MD, MSC, FRCPC \\ Canadian Centre for Applied Research in Cancer Control, Cancer Care Ontario \\ Department of Medicine, University of Toronto \\ Sunnybrook Health Sciences Centre \\ Toronto, ON \\ WINSON Y. CHEUNG, MD, MPH, FRCPC \\ Department of Oncology, University of Calgary \\ Calgary $A B$
}


Claire de Oliveira et al.

JEFFREY S. HOCH, MA, PHD

Center for Healthcare Policy and Research, Public Health Sciences, University of California Davis

St. Michael's Hospital

Institute of Health Policy, Management and Evaluation, University of Toronto

Toronto, ON

STUART PEACOCK, MSC, DPHIL

Canadian Centre for Applied Research in Cancer Control, British Columbia Cancer Agency

School of Population and Public Health, University of British Columbia

Faculty of Health Sciences, Simon Fraser University

Vancouver, BC

MURRAY D. KRAHN, MD, MSC, FRCPC

Toronto Health Economics and Technology Assessment Collaborative

Faculty of Pharmacy and Institute of Health Policy, Management and Evaluation, University of Toronto

University Health Network

Toronto, ON

\begin{abstract}
Background: Costing studies are useful to measure the economic burden of cancer. Comparing costs between healthcare systems can inform evaluation, development or modification of cancer care policies.

Objectives: To estimate and compare cancer costs in British Columbia and Ontario from the payers' perspectives.

Methods: Using linked cancer registry and administrative data, and standardized costing methodology and analyses, we estimated costs for 21 cancer sites by phase of care to determine potential differences between provinces.

Results: Overall, costs were higher in Ontario. Costs were highest in the initial post-diagnosis and pre-death phases and lowest in the pre-diagnosis and continuing phases, and generally higher for brain cancer and multiple myeloma, and lower for melanoma. Hospitalization was the major cost category. Costs for physician services and diagnostic tests differed the most between provinces. Conclusions: The standardization of data and costing methodology is challenging, but it enables interprovincial and international comparative costing analyses.
\end{abstract}

\title{
Résumé
}

Contexte : Les études de coûts sont utiles pour mesurer le fardeau économique du cancer. La comparaison des coûts entre systèmes de santé peut éclairer l'évaluation, l'élaboration ou la modification des politiques pour les soins contre le cancer.

Objectif : Estimer et comparer les coûts pour les soins contre le cancer en ColombieBritannique et en Ontario du point de vue des payeurs.

Méthode: Au moyen d'un registre sur le cancer et de données administratives liées, et au moyen d'analyses et d'une méthodologie des coûts normalisés, nous avons estimé le coût de 
21 sièges du cancer selon les étapes de soins afin de dégager les différences entre les provinces. Résultats : Dans l'ensemble, les coûts sont plus élevés en Ontario. Les coûts étaient plus élevés pour les étapes initiales de post-diagnostic et de pré-mortalité et ils étaient plus bas pour les étapes de pré-diagnostic et de continuité, et généralement plus élevés pour le cancer du cerveau et le myélome multiple, mais moindre pour le mélanome. L'hospitalisation constitue la principale catégorie de coût. Les coûts pour les services de médecins et les tests diagnostics sont ceux qui varient le plus entre les provinces. Conclusion: La standardisation des données et des méthodologies pour les coûts présente un défi, mais elle permet d'effectuer des analyses comparatives des coûts interprovinciales et internationales.

\section{Introduction}

Cancer-related healthcare costs are rising in Canada (CIHI 2011). The most recent estimate of the total cost of cancer care in Canada is $\$ 4.4$ billion for 2008 (PHAC 2014). Given limited financial resources, funders of cancer care struggle to provide patients with the best therapies. Descriptive costing studies reflect the burden to healthcare systems and help translate the effects of health conditions into dollars. Furthermore, comparative studies between healthcare systems can inform evaluation, development or modification of policies and programs related to cancer screening, treatment and delivery of care (Lipscomb et al. 2013). For example, a study comparing resource use for end-of-life care in patients with lung cancer in Ontario and Surveillance, Epidemiology and End Results (SEER) regions in the US found that hospital and emergency room services were used more extensively among Ontario patients, while chemotherapy use was significantly higher among SEER-Medicare patients (Warren et al. 2011). Ontario palliative care was more likely to be administered in the hospital, whereas more home and hospice care was used by SEER-Medicare patients. Such findings could have important policy implications for both countries regarding current end-of-life care patterns, and may identify opportunities for changing practice patterns or programs.

Differences in healthcare delivery, costs and populations across Canada suggest that comparative interprovincial studies could improve cancer care; however, no previous work has undertaken comparative cost analyses between Canadian provinces. Thus far, work has been done in individual provinces, such as British Columbia (BC) (Pataky et al. 2016), Alberta (Fassbender et al. 2009) and Ontario (Krahn et al. 2010; Mittmann et al. 2012, 2014), examining utilization and costs for individual cancer sites and/or single phases of care. One study has estimated costs for various cancer sites in Ontario, but only for the first year after diagnosis (de Oliveira et al. 2013a).

The objectives of this study were to estimate and compare the direct costs for the 21 most common cancer sites, from diagnosis to death, in two large Canadian provinces with similar data holdings, BC and Ontario, from payers' perspectives (the respective Ministries of Health), and to examine potential differences in costs and their drivers. The resulting estimates, based on high-quality evidence, will aid decision-makers on issues, such as efficiency/system 
performance and resource allocation. Despite challenges associated with harmonizing costing methodology and analyses between Canadian provinces, such standardization will enable comparisons at provincial, national and international levels.

\section{Methods}

\section{Patients}

We selected all patients diagnosed with cancer who were 19 years and older from January 1 , 1997, to December 31, 2007, from each provincial cancer registry (BCCA 2010; Hall et al. 2006) based on available data. We included patients with a primary cancer assigned a single, valid International Classification of Diseases for Oncology topography code with a valid histology code (brain, female breast, cervix, colorectal, corpus uteri, esophagus, gastric, head and neck, leukemia, liver, lung, lymphoma, melanoma, multiple myeloma, ovary, pancreas, prostate, renal, testis, thyroid, urinary bladder and a category combining all other tumour sites) (Appendix 1; available at: http://www.longwoods.com/content/25024). We excluded patients with a date of cancer diagnosis that coincided with date of death, not residing in the province of diagnosis, or who did not have a valid provincial health insurance number.

\section{Data}

Data for chemotherapy and radiation therapy (RT) were obtained from the BC Cancer Agency (BCCA) and Cancer Care Ontario. Data on other health services were obtained through Population Data BC in BC, and the Institute for Clinical Evaluative Sciences (ICES) in Ontario (Table 2 in Appendix 1). These data were linked to the respective cancer registry data using patient-unique provincial health plan numbers. Population Data BC and ICES follow practices to protect the privacy and confidentiality of individuals and information. The study was approved by the BC Cancer Agency; the Institutional Review Board at Sunnybrook Health Sciences Centre, Toronto, Canada; and the University of Toronto Research Ethics Boards.

\section{Valuing bealth resources}

Measuring healthcare costs generally requires two components: utilization of data (i.e., quantity of resources) and unit cost data (i.e., cost of resources). This information was collected for chemotherapy, RT, in-patient hospitalizations, same-day surgery/procedures, physician services, diagnostic tests, out-patient prescription drugs and home and community care. Total cost estimates for in-patient hospitalizations and same-day surgery/procedures were obtained by multiplying the resource intensity weight (measure of resource utilization intensity) by the cost per weighted case (unit cost) (Baladi 1996; CIHI 1995; Pink and Bolley 1994; Wodchis et al. 2011). Cost estimates for other resources were available in the data or obtained from other sources (Earle et al. 1999; Wodchis et al. 2011). These costing methods follow the guidelines of the Canadian Agency for Drugs and Technologies in Health (CADTH 2006) and are based on previous cancer costing work in Ontario (de Oliveira et al. 2013a; Krahn et al. 2010). Healthcare costs included the costs of cancer care and the costs of caring for other health problems. 


\section{Harmonization}

Because of privacy legislation, data were analyzed separately in each province; this limited our ability to undertake aggregate analyses. Nonetheless, we tried to define and measure all pertinent variables in the same manner. Some challenges are described below.

\section{Date of diagnosis}

The cancer registries defined diagnosis date differently. BC legally mandates the reporting of cancer (active registration); diagnosis is based on the date of cytological or histological diagnosis. Ontario has passive registration where ascertainment of diagnosis date relies on various administrative records. Date of diagnosis is the earliest date of hospital admission with a cancer diagnostic code, biopsy, visit to a cancer centre or death (if cause of death is cancer). To address this difference, the diagnosis date for $\mathrm{BC}$ patients diagnosed in the hospital was recoded as the date of hospital admission.

\section{Cost of chemotherapy}

In Ontario, all chemotherapy is delivered at provincial cancer centres. The provincially funded New Drug Funding Program and the Ontario Drug Benefit (ODB) Program also provide chemotherapy drugs; this required a careful survey of the data to capture chemotherapy accurately. BCCA's Provincial Systemic Therapy Program funds chemotherapy; drug costs are available from program data. Appointment records for chemotherapy delivery outside BCCA regional cancer centres were not available; hence, a mean chemotherapy delivery cost was assigned to unique patient-days from the Systemic Therapy Program dispensing records.

\section{Cost of $R T$}

Ontario uses the National Hospital Productivity Improvement Program codes to measure RT resource intensity, whereas $\mathrm{BC}$ does not; this made direct utilization comparison cumbersome. Furthermore, RT costs could not be obtained from the BC data; thus, we applied the Ontario cost per fraction estimate (Earle et al. 1999) to BC utilization data.

\section{Cost of physician services}

Canadian physicians are paid in several ways - fee-for-service, salary, capitation, alternate funding arrangements and combinations of these. The Ontario Health Insurance Plan (OHIP) claims database includes fee-for-service payments and shadow billings (that is, a way to track services provided by physicians who are not paid fee-for-service). However, the BC Medical Services Plan (MSP) data only include fee-for-service billings (BC MOH 2012b). $\mathrm{BC}$ oncologists are paid through alternative funding arrangements with the $\mathrm{BCCA}$, so we used the BCCA appointment records and unit costs from the MSP fee schedule to assign costs to oncologist visits. We also assigned "treatment planning" costs to radiation oncologist visits, derived from the OHIP fee schedule, based on the complexity of the RT delivered. 


\section{Cost of diagnostic tests}

The cost of diagnostic tests, including the professional and technical components, was obtained from the MSP and OHIP databases for BC and Ontario, respectively, with a few exceptions. For example, the costs of histology and specialized cancer-specific diagnostic tests were not included in the MSP (they are covered by other provincial budgets). We were unable to capture all costs through alternative data sources; thus, we underestimated the true cost in BC.

\section{Cost of out-patient prescription drugs}

In Canada, out-patient prescription drugs are covered under public and private insurance plans, or paid out-of-pocket. In BC, PharmaNet provides data on all out-patient prescription drugs, including those covered by BC PharmaCare (publicly paid plan) (BC MOH 2012c). This plan was age-based until 2002 and then became income-based (Morgan et al. 2006). In Ontario, only data on out-patient drugs paid by the publicly paid ODB program, which covers individuals aged 65 years and older and special cases (MOHLTC 2014), were available, which limited our ability to account for all drug-related costs. Thus, to ensure comparability between provinces, we included publicly paid prescription drugs in BC only. The samples of patients covered under the publicly paid plans in each province were quite similar.

\section{Cost of home and community care}

Home and community care is organized under different names in each province. In particular, in BC, complex continuing care is not defined in the same manner as in Ontario (and thus could not be compared individually), but is provided under home and community care (in Ontario, this is defined as other institution-based care for people who have long-term illnesses or disabilities typically requiring skilled, technology-based care not available at home or in long-term care facilities) (BC MOH 2012a). To overcome differences in the structure of home and community care data, and ensure the inclusion of comparable services, we aggregated all home and community care, including complex continuing care, long-term care, home nursing and home support, into one category within each province. Data on home and community care were missing for two health authorities in BC in later years of observation, so these values were imputed.

\section{Cost of other care}

Finally, few facilities in BC reported data on emergency department visits and/or other ambulatory care to the National Ambulatory Care Reporting System during the analysis period; given the availability of limited data (which would not enable an accurate comparison), we excluded this type of care from our analysis.

\section{Estimating healthcare costs over time: phase of care approach}

We used a phase-based approach (Baker et al. 1991; Brown et al. 1999; Yabroff et al. 2008) to estimate the costs incurred before and after diagnosis, and to deal with patients who 
entered and exited or were censored from the study cohort at different times. All patients had a pre-diagnosis phase, defined as the three months before the date of diagnosis. This phase typically includes diagnostic testing to establish the cancer diagnosis (Christensen et al. 2012; Hornbrook et al. 2013). We divided the time between diagnosis and death into the following three phases based on clinical relevance and join point analysis (Baker et al. 1991; Kim et al. 2000; Yabroff et al. 2008): (1) initial care, which includes the primary course of therapy and any adjuvant therapy, defined as the six months after diagnosis (including date of diagnosis); (2) continuing care, which encompasses surveillance and active follow-up treatment for cancer recurrence and/or new primary cancer, with costs expressed as annual estimates; and (3) terminal care, which captures intensive services, often palliative in nature, defined as the 12 months before death. Patients who died had their time first assigned to the terminal phase; their remaining time, and all time of patients who survived, was then assigned to the initial phase and then the continuing phase (Brown et al. 1999; Yabroff et al. 2008). Patients with cancer who died of any cause during the analysis period were included.

We estimated mean costs for each cancer by phase of care and respective $95 \%$ confidence intervals. We also examined costs by resource (as defined above) for the four most common cancers (breast, colorectal, lung and prostate) for the initial and terminal phases to understand the cost drivers, and to enable detailed interprovincial comparisons of cost components. (Costs by resource for all cancers are available upon request.) Costs were adjusted to 2009 Canadian dollars (Statistics Canada 2014).

\section{Results}

\section{Patients' characteristics}

Table 1 describes patients' characteristics in Ontario $(N=402,399)$ and BC $(N=150,971)$. The proportions of patients by cancer site were approximately the same in both provinces, except for prostate, lung, breast, colorectal, thyroid (in line with previous findings; Thyroid Cancer Canada 2014) and lymphoma. Patients' mean age was 65 years; approximately 52\% were male. Slightly more patients were in the two lower-income quintiles in BC; the opposite held for Ontario. In both provinces, $85 \%$ of patients lived in urban settings and about $1 \%$ lived in long-term care facilities at time of diagnosis.

\section{Mean costs by phase of care}

Mean total costs across phases were generally higher in Ontario than in BC, with greater variation in costs across cancers for Ontario. For most cancer sites and phases of care, confidence intervals for costs for each province did not overlap, suggesting significant differences. Nonetheless, the ranking of costs by cancer was generally the same at the tail ends of the distributions in both provinces. For the pre-diagnosis phase, costs varied from $\$ 733$ to $\$ 3,833$ in $\mathrm{BC}$ and $\$ 1,016$ to around $\$ 4,660$ in Ontario (Table 2, available at: http://www.longwoods. com/content/25024). In both provinces, costs were highest for brain and bladder, and lowest for renal and thyroid cancers. All patients contributed to this phase. 
Claire de Oliveira et al.

TABLE 1. Patients' characteristics

\begin{tabular}{|c|c|c|}
\hline Characteristic & British Columbia, N (\%) & Ontario, N (\%) \\
\hline Total & $|50,97|$ & 402,399 \\
\hline \multicolumn{3}{|l|}{ Cancer site } \\
\hline Prostate & $27,828(18.4)$ & $68,940(17.1)$ \\
\hline Breast & $23,965(15.9)$ & $68,709(17.1)$ \\
\hline Colorectal & 19,033 (12.6) & $58,659(14.6)$ \\
\hline Lung & | 8,383 (12.2) & $42,046(10.4)$ \\
\hline Melanoma & $5,953(3.9)$ & $17,059(4.2)$ \\
\hline Bladder & $3,561(2.4)$ & $12,580(3.1)$ \\
\hline Head and neck & $4,307(2.9)$ & $12,462(3.1)$ \\
\hline Corpus uteri & $4,126(2.7)$ & $12,352(3.1)$ \\
\hline Thyroid & $2,058(1.4)$ & । I,448 (2.8) \\
\hline Lymphoma & $7,487(5.0)$ & $10,467(2.6)$ \\
\hline Renal & $3,155(2.1)$ & $10,204(2.5)$ \\
\hline Gastric & $2,757(1.8)$ & $8,107(2.0)$ \\
\hline Leukemia & $3,78 \mid(2.5)$ & $8,052(2.0)$ \\
\hline Ovary & $2,246(1.5)$ & $7,167(1.8)$ \\
\hline Pancreas & $3,044(2.0)$ & $6,358(1.6)$ \\
\hline Brain & $2,115(1.4)$ & $5,462(1.4)$ \\
\hline Cervix & $|, 57|(1.0)$ & $4,819(1.2)$ \\
\hline Esophagus & $1,667(1.1)$ & $4,349(1.1)$ \\
\hline Myeloma & $1,812(1.2)$ & $4,315(1.1)$ \\
\hline Testis & ।, $044(0.7)$ & $3,054(0.8)$ \\
\hline Liver & $1,310(0.9)$ & $2,640(0.7)$ \\
\hline Other tumours & $9,768(6.5)$ & $23,150(5.8)$ \\
\hline \multicolumn{3}{|l|}{ Age at diagnosis } \\
\hline Mean (SD) & $65.0(14.00)$ & $63.5(13.95)$ \\
\hline Median (IQR) & $66(56-75)$ & $65(54-74)$ \\
\hline \multicolumn{3}{|l|}{ Sex } \\
\hline Female & $71,599(47.4)$ & $196,017(48.7)$ \\
\hline Male & $79,372(52.6)$ & $206,382(51.3)$ \\
\hline
\end{tabular}




\begin{tabular}{|c|c|c|}
\hline Characteristic & British Columbia, N (\%) & Ontario, $N(\%)$ \\
\hline \multicolumn{3}{|l|}{ Neighbourhood income quintile } \\
\hline Missing & $1,563(1.0)$ & $1,683(0.4)$ \\
\hline I-Low & $32,199(21.3)$ & $75,662(18.8)$ \\
\hline 2 - Medium-low & $29,648(19.6)$ & $81,882(20.3)$ \\
\hline 3 - Medium & $28,877(19.1)$ & $79,363(19.7)$ \\
\hline 4 - Medium-high & $28,917(19.2)$ & $79,577(19.8)$ \\
\hline 5 - High & $29,767(19.7)$ & $84,232(20.9)$ \\
\hline \multicolumn{3}{|l|}{ Urban/rural residence } \\
\hline Missing & $130(0.1)$ & $0(0.0)$ \\
\hline Urban & 127,934 (84.7) & $342,751(85.2)$ \\
\hline Rural & $22,907(15.2)$ & $59,648(14.8)$ \\
\hline Residence in long-term care facility & ।,953 (1.3) & $3,87 \mid(1.0)$ \\
\hline
\end{tabular}

$\mathrm{IQR}=$ interquartile range; $\mathrm{SD}=$ standard deviation

Costs increased greatly in the initial phase of care (Table 2). These varied from just over $\$ 3,000$ to $\$ 32,376$ in $\mathrm{BC}$ and from $\$ 5,250$ to $\$ 43,409$ in Ontario. Costs were highest for cancers with poor survival rates, such as brain, esophageal, pancreatic and gastric cancers, and lowest for those with high survival rates, such as melanoma, thyroid and prostate cancers. Approximately $82 \%$ of patients contributed to this phase.

Costs in the continuing phase varied from $\$ 1,978$ and $\$ 2,858$ to around $\$ 16,992$ and $\$ 19,340$ for BC and Ontario, respectively (Table 2). Mean total continuing care costs were highest for multiple myeloma and lowest for melanoma, thyroid, cervical and testicular cancers. Approximately $77 \%$ of patients were included in this phase.

Mean costs were highest for the terminal phase of care and varied from about $\$ 33,632$ to $\$ 75,950$ in BC and $\$ 39,645$ to $\$ 89,544$ in Ontario (Table 2). Costs were higher for brain cancer and lower for melanoma. The high costs for testicular cancer, $\$ 75,911$ and $\$ 74,558$ in BC and Ontario, respectively, were mainly driven by a small group of older males. Approximately $45 \%$ of our patient sample died before the end of our observation period and thus contributed to this phase.

Mean costs for the initial and terminal phases by resource for the four common cancers In both the initial and terminal phases, in-patient hospitalizations represented the highest costs for all cancers (Figure 1). In the initial phase, we found small interprovincial differences in the costs for some resources, such as same day-surgery and RT. For example, lung cancer costs with same-day surgery were virtually identical in BC (\$601) and Ontario (\$635). We found large cost differences for chemotherapy, especially for prostate cancer, largely owing to the inclusion of hormone therapy under systemic therapy in BC ( $\$ 1,024$ in $\mathrm{BC}$ versus $\$ 18$ in Ontario), 
physician services and diagnostic tests. Cost estimates for physician services were systematically higher in BC than in Ontario for all cancer sites, while the opposite held for diagnostic tests.

In the terminal phase, we found small interprovincial differences in the costs for same-day surgery, RT and, in some cancers, home and community care and in-patient hospitalizations (Figure 2). For example, for same-day surgery, the cost difference between provinces was less than $\$ 30$ for any given cancer. The cost differences for out-patient prescription drugs, diagnostic tests and physician services were large. In particular, we found the same cost pattern for the latter two resources similar to that in the initial phase of care.

FIGURE 1. Mean costs (2009 Canadian dollars) for the initial phase of care by resource for the four most common cancers in $\mathrm{BC}$ and $\mathrm{ON}$

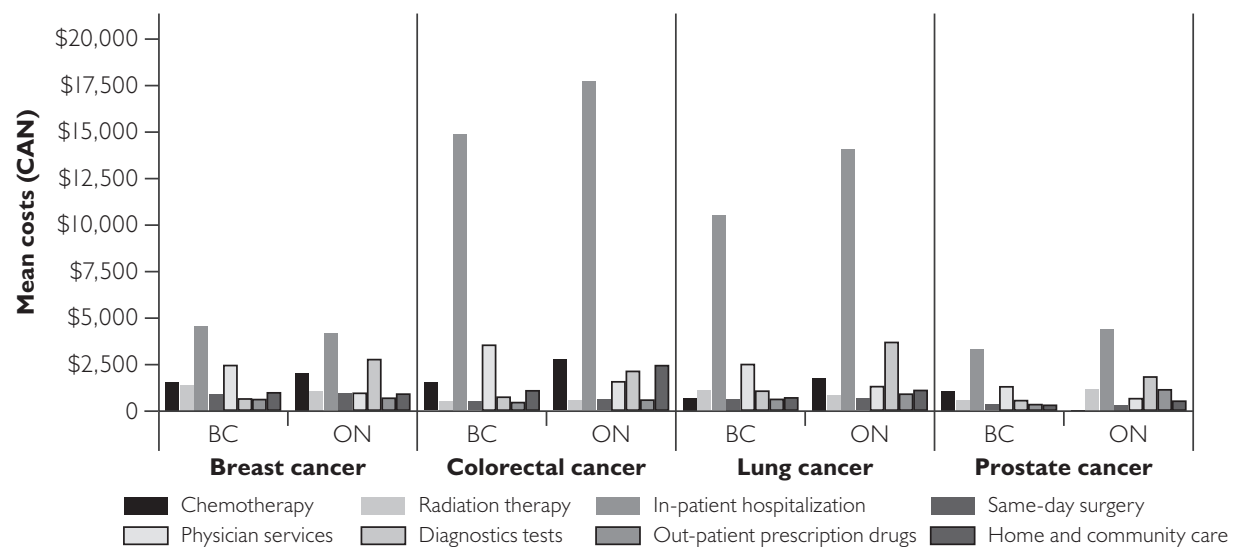

FIGURE 2. Mean costs (2009 Canadian dollars) for the terminal phase by resource for the four most common cancers in $\mathrm{BC}$ and $\mathrm{ON}$

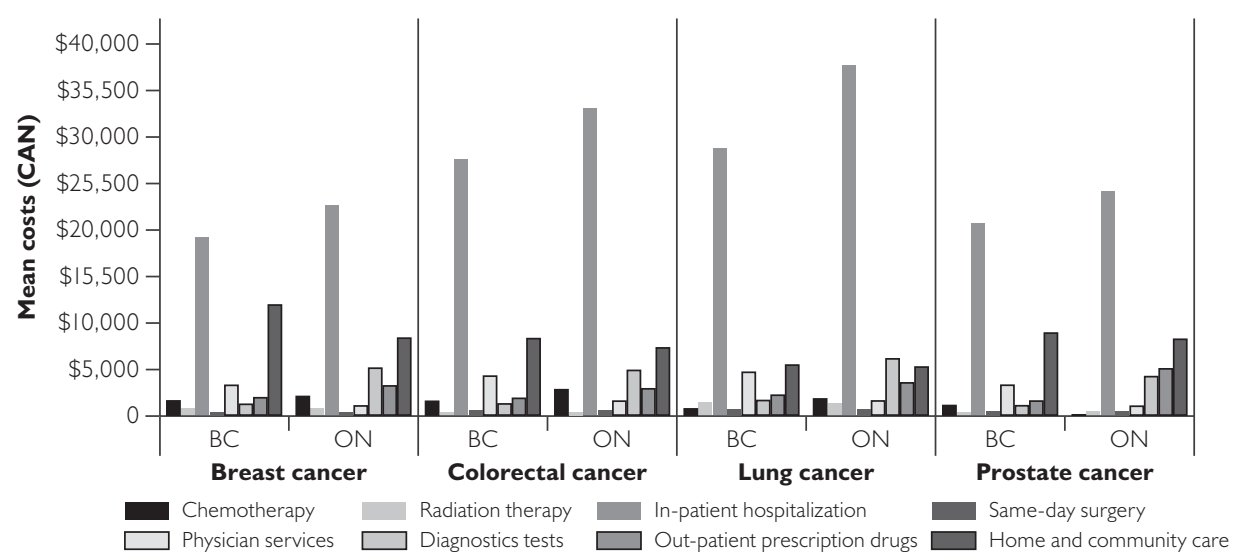

\section{Discussion}

In both provinces, and across cancers, costs were highest in the terminal phase, followed by the initial phase. On average, costs were highest among cancers with poor survival rates, such as brain cancer, and lowest for melanoma, with better survival. Our ranking of costs is in line with other work from 
Ontario (de Oliveira et al. 2013a; Krahn et al. 2010) and the US (Yabroff et al. 2008). Previous research also found that (net) costs in the initial and terminal phases of care in the SEER-Medicare population were highest for brain cancer and lowest for melanoma (Yabroff et al. 2008).

Cancer-related treatment protocols are expected to be similar across Canada; yet, costs were generally higher in Ontario than in BC. Most cost differences are likely due to difficulties in harmonizing costing methods, missing data and the need to impute data. Some interprovincial cost differences were specific to a resource category. For most cancers, hospitalization costs were higher in Ontario owing to unit cost estimates (i.e., higher cost per weighted case values). Lower costs for diagnostic tests in $\mathrm{BC}$ were owing to the fact that some tests are not included in the MSP. Over our analysis period, there were many changes in Ontario with the introduction of alternative payment plans that affected the way physicians reported services rendered to patients. These may not be fully captured in the administrative data. Thus, we speculate that lower costs for physician services in Ontario may be because of an underestimation of service use through shadow billings, for example. Furthermore, differences between provinces are likely a reflection of differences in the organization and coverage of services provided, such as home and community care, and the generosity of coverage of out-patient prescription drugs under each public healthcare plan.

The findings from this study may help decision-makers on issues around health system efficiency and system performance. In particular, these results can provide insight on issues such as resource allocation (within and across cancer sites) and planning of future provincial healthcare budgets. In addition, this work may provide some understanding of system efficiency/performance, namely, on how provinces can learn from one another regarding successful cost-containment strategies and improvements around quality of care.

Undertaking cross-national or within-country costing studies can be challenging because administrative data, medical records and cancer registries were not designed for this type of research (Lipscomb et al. 2013). Differences in the organization of healthcare systems (coverage policies, payment of physicians and submission of claims) can make cost comparisons quite complex (Lipscomb et al. 2013). Even within Canada, comparison of cancer-specific care, such as chemotherapy and RT, requires care because data are not recorded in a standard manner across provinces, and cost estimates are rarely available in the data. Comparison of hospitalization costs presents fewer challenges, as standard data are reported in the same database across Canada, except for Quebec. However, despite the standard data structure, differences in coding versions (CIHI 2009) and cost per weighted case estimates over time can introduce bias between jurisdictions. This is particularly important, as hospitalizations represent a large portion of the total cost. Attention may also be required to appropriately capture costs for physician services (fee-for-service versus alternative payment plans) and diagnostic tests (physician and technician billings versus global budgets), and ensure that resource categories include the same type of care (for example, home and community care). Yet, the standardization of the costing methods among provinces will enable researchers to obtain accurate cost estimates at the national level and can aid in making international comparisons. This is one of the first 
studies to undertake this type of comparative analysis; while some limitations exist, this work has provided relevant insights. Future work should focus on developing and furthering the harmonization of costing methods between provinces.

Our study used rich administrative healthcare data and included large population-based samples of adults over the age of 18 years in BC and Ontario. We included cancers, such as multiple myeloma and those typically diagnosed among younger adults, such as thyroid and testicular cancers, which have not been examined previously, particularly in studies from the US examining Medicare data (patients aged 65 years and older) (Yabroff et al. 2008). We used detailed costing methods and considered the majority of resources paid for by the BC and Ontario Ministries of Health under comprehensive universal healthcare insurance plans. Furthermore, our study is the first to estimate phase-specific costs for all major cancers in BC and Ontario.

There were some limitations. We were not able to compare costs for emergency department visits due to the lack of data in BC. Some cost estimations required making assumptions and extrapolations; in some cases, we were unable to account for all relevant costs. Although the number and type of individuals covered by the ODB and PharmaCare were quite similar, the drugs covered under the two plans may differ. Furthermore, interprovincial differences in chemotherapy and out-patient drug costs suggest hormone therapy (for example, for prostate cancer) may have been classified differently. We could not present costs by cancer stage because stage information was not available in either province for our analysis period. Previous research has found that costs are higher at advanced stages in which survival is generally short (Yabroff et al. 2008). We did not examine the relative importance of age on average costs. Other work suggests that costs of cancer care are higher for younger patients (de Oliveira et al. 2013b). We estimated all healthcare costs incurred by patients, not net cancer costs (i.e., the difference between patients with and without cancer). Future work will use a matched case-control methodology (Brown et al. 1995, 2002; Taplin et al. 1995) to estimate net costs across phases of care.

\section{Conclusion}

Cancer exerts an enormous health and economic burden, which will likely rise in coming decades in Canada. Our findings highlight important cost differences between phases of care, cancer sites and resources within and between provinces. Comparative cost studies present many challenges but enable analyses within and between countries, and can produce comparable estimates for research, policy and decision-making.

\section{Acknowledgements}

The BC Cancer Agency, the BC Ministry of Health and the BC Vital Statistics Agency approved access to and use of the data facilitated by Population Data BC for this study. In Ontario, this study was supported by the Institute for Clinical Evaluative Sciences (ICES), which is funded by an annual grant from the Ministry of Health and Long-Term Care (MOHLTC). All inferences, opinions and conclusions drawn in this paper are those of the authors, and do not reflect the opinions or policies of the Data Stewards and are 
independent from the funding sources. No endorsement by the ICES or the MOHLTC is intended or should be inferred. Parts of this material are based on data and information compiled and provided by the Canadian Institute for Health Information (CIHI). However, the analyses, conclusions, opinions and statements expressed herein are those of the authors, and not necessarily those of CIHI.

This project was funded by a research grant from the Canadian Cancer Society Research Institute (grant \# 020200), as well as the Canadian Centre for Applied Research in Cancer Control (Canadian Cancer Society Research Institute, grant \#019789). Dr. Peacock is supported by the Leslie Diamond Chair in Cancer Survivorship at the Faculty of Health Sciences, Simon Fraser University. Dr. Krahn is supported by the F. Norman Hughes Chair in Pharmacoeconomics at the Faculty of Pharmacy, University of Toronto.

Correspondence may be directed to: Claire de Oliveira, Independent Scientist/Health Economist, Centre for Addiction and Mental Health, Institute for Mental Health Policy Research, 33 Russell Street, Room T414, Toronto, ON M5S 2S1; tel.: 416-535-8501 ext. 36098; e-mail: claire.deoliveira@camb.ca.

\section{References}

Baker, M.S., L.G. Kessler, N. Urban and R.C. Smucker. 1991. "Estimating the Treatment Costs of Breast and Lung Cancer." Medical Care 29: 40-49.

Baladi, J.F. 1996. A Guidance Document for the Costing Process, Version 1.0. Ottawa, ON: Canadian Coordinating Office for Health Technology Assessment.

British Columbia Cancer Agency Registry Data. 2012a. "BC Cancer Registry." Retrieved March 7, 2011. <www. bccancer.bc.ca/HPI/CancerStatistics/>.

British Columbia Ministry of Health (BC MOH). 2012a. Home and Community Care (Continuing Care). Population Data BC. Data Extract. MOH (2012). Retrieved June 18, 2012. <www.popdata.bc.ca/data/internal/ health/hcc>.

British Columbia Ministry of Health (BC MOH). 2012b. Medical Services Plan (MSP) Payment Information File. Population Data BC. Data Extract. MOH (2012). Retrieved June 18, 2012. <www.popdata.bc.ca/data/ internal/health/msp >.

British Columbia Ministry of Health (BC MOH). 2012c. PharmaNet. BC Ministry of Health. Data Extract. Data Stewardship Committee (2012). Retrieved June 18, 2012. <www.popdata.bc.ca/data/external/PharmaNet>. Brown, M.L., G.F. Riley, A.L. Potosky and R.D. Etzioni. 1999. “Obtaining Long-Term Disease Specific Costs of Care: Application to Medicare Enrolees Diagnosed with Colorectal Cancer." Medical Care 37(12): 1249-59.

Brown, M.L., G.F. Riley, N. Schussler and R. Etzioni. 2002. “Estimating Health Care Costs Related to Cancer Treatment from SEER-Medicare Data." Medical Care 40(Suppl.): IV-104-17.

Canadian Agency for Drugs and Technology in Health (CADTH). 2006. Guidelines for Economic Evaluation of Pharmaceuticals (3rd ed.). Ottawa, ON: Canadian Coordinating Office for Health Technology Assessment.

Canadian Institute of Health Information (CIHI). 1995. Resource Intensity Weights: Summary of Methodology 1995/1996. Ottawa, ON: Author.

Canadian Institute for Health Information (CIHI). 2009. Regrouping Historical Data - CIHI Reference Document. Ottawa, ON: Author.

Canadian Institute for Health Information (CIHI). 2011. National Health Expenditure Trends, 1975 to 2011. Ottawa, ON: Author. 
Christensen, K.G., M. Fenger-Grøn, R. Flarup and P. Vedsted. 2012. “Use of General Practice, Diagnostic Investigations and Hospital Services before and after Cancer Diagnosis - A Population-Based Nationwide Registry Study of 127,000 Incident Adult Cancer Patients." BMC Health Services Research 12: 224.

de Oliveira, C., K. Bremner, R. Pataky, N. Gunraj, K. Chan, S. Peacock et al. 2013a. “The Costs of Cancer Care before and after Diagnosis for the 21 Most Common Cancers in Ontario." Canadian Medical Association Journal Open 1(1): E1-E8. de Oliveira, C., K. Bremner, R. Pataky, N. Gunraj, M. Haq, K. Chan et al. 2013b. "Evaluation of Trends in the Cost of Initial Cancer Treatment in Ontario." Canadian Medical Association Journal Open 1(4): E151-58.

Earle, C., D. Coyle, A. Smith, O. Agboola and W.K. Evans. 1999. "The Cost of Radiotherapy at an Ontario Regional Cancer Centre: A Revaluation." Critical Reviews in Oncology/Hematology 32: 87-93.

Fassbender, K., R.L. Fainsinger, M. Carson and B.A. Finegan. 2009. “Cost Trajectories at the End of Life: The Canadian Experience." Journal of Pain Symptom Management 38(1): 75-80.

Hall, S., K. Schulze, P. Groome, W. Mackillop and E. Holowaty. 2006. “Using Cancer Registry Data for Survival Studies: The Example of the Ontario Cancer Registry." Journal of Clinical Epidemiology 59: 67-76.

Hornbrook, M.C., P.A. Fishman, D.P. Ritzwoller, J. Elston-Lafata, M.C. O'Keeffe-Rosetti and R.G. Salloum. 2013. "When Does An Episode of Care for Cancer Begin?" Medical Care 51(4): 324-29.

Kim, H.J., M.P. Fay, E.J. Feuer and D.N. Midthune. 2000. "Permutation Tests for Joinpoint Regression with Applications to Cancer Rates." Statistics in Medicine 19(3): 335-51.

Krahn, M.D., B. Zagorski, A. Laporte, S.M. Alibhai, K.E. Bremner, G. Tomlinson et al. 2010. "Healthcare Costs Associated with Prostate Cancer: Estimates from A Population-Based Study." British Journal of Urology International 105: 338-46.

Lipscomb, J., K.R. Yabroff, M.C. Hornbrook, A. Gigli, S. Francisci, M. Krahn et al. 2013. “Comparing Cancer Care, Outcomes, and Costs across Health Systems: Charting the Course." Journal of the National Cancer Institute Monographs (46): 124-30.

Ministry of Health and Long-Term Care (MOHLTC). 2014 (. The Ontario Drug Benefit (ODB) Program. Retrieved December 29, 2014. <https://www.ontario.ca/page/get-coverage-prescription-drugs>.

Mittmann, N., P.K. Isogai, R. Saskin, N. Liu, J.M. Porter, M.C. Cheung et al. 2012. “Population-Based Home Care Services in Breast Cancer: Resources and Costs." Current Oncology 19(6): e383-91.

Mittmann, N., N. Liu, J.M. Porter, S.J. Seung, P.K. Hon, Isogai, R. Saskin. et al. 2014. “Utilization and Costs of Home Care for Patients with Colorectal Cancer: A Population-Based Study." Canadian Medical Association Journal Open 2(1): E11-E17.

Morgan, S., R.G. Evans, G.E. Hanley, P.A. Caetano and C. Black. 2006. "Income-Based Drug Coverage in British Columbia: Lessons for BC and the Rest of Canada." Healthcare Policy 2(2): 115-27.

Pataky, R., W. Cheung, C. de Oliveira, K. Bremner, K. Chan, J. Hoch et al. 2016. "Population-Based Trends in Systemic Therapy Use and Cost for Cancer Patients in the Last Year of Life." Current Oncology 23(S1): S32-S41. Public Health Agency of Canada (PHAC). 2014. Economic Burden of Illness in Canada 2005-2008. Ottawa, ON: Author. Pink, G.H. and H.B. Bolley. 1994. "Physicians in Health Care Management: 3: Case Mix Groups and Resource Intensity Weights: An Overview for Physicians." Canadian Medical Association Journal 150: 889-94.

Statistics Canada. 2012. The Consumer Price Index. Ottawa, ON: Author. Retrieved February 17, 2017. $<$ http://www.statcan.gc.ca/pub/62-001-x/62-001-x2012006-eng.pdf>.

Taplin, S.H., W. Barlow, N. Urban, M.T. Mandelson, D.J. Timlin, L. Ichikawa et al. 1995. “Stage, Age, Comorbidity, and Direct Costs of Colon, Prostate, and Breast Cancer Care." Journal of the National Cancer Institute 87: 417-26.

Thyroid Cancer Canada. 2014. Quick Facts E Figures. Retrieved December 23, 2014. <www. thyroidcancercanada.org/quick-facts-and-figures.php?lang=en $>$.

Warren, J.L., L. Barbera, K.E. Bremner, K.R. Yabroff, J.S. Hoch, M.J. Barrett et al. 2011. “End-of-Life Care for Lung Cancer Patients in the United States and Ontario." Journal of the National Cancer Institute 103(11): 853-62. Wodchis, W.P., K. Bushmeneva, M. Nikitovic and I. McKillop. 2011. Guidelines on Person-Level Costing Using Administrative Databases in Ontario. Toronto, ON: Health System Performance Research Network.

Yabroff, K.R., E.B. Lamont, A. Mariotto, J.L. Warren, M. Topor, A. Meekins et al. 2008. "Cost of Care for Elderly Cancer Patients in the United States." Journal of the National Cancer Institute 100: 630-41. 